\title{
Article \\ Growth Properties of Carbon Nanowalls on Nickel and Titanium Interlayers
}

\author{
May Tran Thi ${ }^{1}$, Seokhun Kwon ${ }^{1}$, Hyunil Kang ${ }^{1}$, Jung-Hyun Kim ${ }^{2}{ }^{\mathbb{D}}$, Yong-Kyu Yoon ${ }^{3} \mathbb{D}$ and Wonseok Choi ${ }^{1, *} * \mathbb{D}$ \\ 1 Department of Electrical Engineering, Hanbat National University, Daejeon 34158, Korea; \\ tranthimayk61hoa@gmail.com (M.T.T.); kwon1567@naver.com (S.K.); hikang@hanbat.ac.kr (H.K.) \\ 2 Department of Advanced Materials Engineering, Hanbat National University, Daejeon 34158, Korea; \\ jhkim2011@hanbat.ac.kr \\ 3 School of Electrical and Computer Engineering, University of Florida, Gainesville, FL 32611, USA; \\ ykyoon@ece.ufl.edu \\ * Correspondence: wschoi@hanbat.ac.kr
}

check for updates

Citation: Tran Thi, M.; Kwon, S.; Kang, H.; Kim, J.-H.; Yoon, Y.-K.; Choi, W. Growth Properties of Carbon Nanowalls on Nickel and Titanium Interlayers. Molecules 2022, 27, 406. https://doi.org/10.3390/ molecules27020406

Academic Editor: Dipendu Saha

Received: 9 December 2021

Accepted: 5 January 2022

Published: 9 January 2022

Publisher's Note: MDPI stays neutral with regard to jurisdictional claims in published maps and institutional affiliations.

Copyright: (c) 2022 by the authors. Licensee MDPI, Basel, Switzerland. This article is an open access article distributed under the terms and conditions of the Creative Commons Attribution (CC BY) license (https:// creativecommons.org/licenses/by/ $4.0 /)$.

\begin{abstract}
This research is conducted in order to investigate the structural and electrical characteristics of carbon nanowalls (CNWs) according to the sputtering time of interlayers. The thin films were deposited through RF magnetron sputtering with a 4-inch target (Ni and Ti) on the glass substrates, and the growth times of the deposition were 5, 10, and $30 \mathrm{~min}$. Then, a microwave plasma-enhanced chemical vapor deposition (PECVD) system was used to grow CNWs on the interlayer-coated glass substrates by using a mixture of $\mathrm{H}_{2}$ and $\mathrm{CH}_{4}$ gases. The FE-SEM analysis of the cross-sectional and planar images confirmed that the thickness of interlayers linearly increased according to the deposition time. Furthermore, CNWs grown on the Ni interlayer were taller and denser than those grown on the Ti interlayer. Hall measurement applied to measure sheet resistance and conductivity confirmed that the electrical efficiency improved significantly as the $\mathrm{Ni}$ or $\mathrm{Ti}$ interlayers were used. Additionally, UV-Vis spectroscopy was also used to analyze the variations in light transmittance; CNWs synthesized on Ni-coated glass have lower average transmittance than those synthesized on Ti-coated glass. Based on this experiment, it was found that the direct growth of CNW was possible on the metal layer and the CNWs synthesized on Ni interlayers showed outstanding structural and electrical characterizations than the remaining interlayer type.
\end{abstract}

Keywords: carbon nanowall; RF-magnetron sputtering; PECVD; interlayer; thickness

\section{Introduction}

Carbon-based materials are easy to process, relatively inexpensive, chemically and structurally stable, and have high electrical conductivity [1-4]. For these reasons, they have attracted attention for a long time, and many studies on their application on semiconductors, sensors, thin films, materials, storage, and displays have been conducted [5-7]. Among carbon-based nanomaterials, the carbon nanowall (CNW), which was discovered while synthesizing carbon nanotubes (CNTs), is a type of material wherein multilayers of graphene are vertically synthesized on a circuit board [3,4]. Moreover, the CNW has the widest reactive surface, as well the as merits of excellent electron mobility, mechanical strength, and chemical stability, due to its carbon and graphene components. The physical properties and the shape of CNWs are highly dependent on the processing conditions and the quality of the substrates used [1-7]. In addition, the electrical characteristic of CNWs is changed by parameters, such as area density, height, and thickness.

However, CNWs are difficult to deposit on a glass substrate due to their low adherence. Under very small stresses, the walls easily break down, and the substrate and CNW can be separated [8-11]. In order to solve these issues and increase the utilization of CNW for devices, an intermediate layer (interlayer) was inserted between the CNW and the substrate. Recently, titanium is a widely used interlayer with excellent thermal stability 
and chemical safety, as well as a high fine hardness that can dissolve the oxides remaining on the substrate surface and act as a compliant layer that reduces shear stress at the coatingsubstrate interface [12,13]. Meanwhile, the nickel interlayer provides excellent adhesion properties for the subsequent coating layers [14]. The unique functional properties of nickel include its ability to be slowly oxidized by air at room temperature, as well as its corrosion resistance, hardness, and erosion resistance, and uniform layer thickness, even on complicated components [15].

In this work, nickel (Ni) and titanium (Ti) are used as intermediate layers, then the $\mathrm{CNW}$ is grown by injecting a mixture of hydrogen $\left(\mathrm{H}_{2}\right)$ and methane $\left(\mathrm{CH}_{4}\right)$ gases into the interlayer deposited in a microwave plasma-enhanced chemical vapor deposition (PECVD) chamber. The interlayer features are evaluated, and the growth characteristics of $\mathrm{CNW}$ grown directly on the glass substrate are compared to those of the CNW grown on the interlayer.

\section{Experimental Details}

\subsection{Interlayer Deposition}

The $2 \times 2 \mathrm{~cm}^{2}$ glass substrates were cleaned with an ultrasonic cleaner using trichloroethylene (TCE), acetone, methanol, and deionized (D.I.) water, in that order, for 10 min each, to remove impurities except for the gases required to synthesize the CNWs. Nitrogen gas was used to dry the cleaned glass. The cleaned glass wafers were then placed in a radio frequency (RF) magnetron sputtering system chamber with a base vacuum maintained below $10^{-5}$ Torr. Ar gas (40 sccm) was injected as the sputtering gas, and the working pressure was maintained at $3 \times 10^{-3}$ Torr. Four-inch $\mathrm{Ni}$ and $\mathrm{Ti}$ targets were used. The deposition time $(5,10$, and $30 \mathrm{~min})$ was varied at $50 \mathrm{~W}$ RF power and $1.0 \times 10^{-2}$ Torr working vacuum, and each was attached to a substrate via spinning at $1700 \mathrm{rph}$ during deposition.

\subsection{Carbon Nanowall Growth}

For the synthesis of the CNWs, microwave PECVD was used. A base pressure of $1 \times 10^{-5}$ Torr was maintained in the PECVD chamber, methane $\mathrm{CH}_{4}$ gas was injected into the chamber at $20 \mathrm{sccm}$, and $\mathrm{H}_{2}$ gas was injected at $40 \mathrm{sccm}$. In this stage, the working pressure in the chamber was kept at $1 \times 10^{-2}$ Torr, and the CNWs were synthesized by using $1200 \mathrm{~W}$ microwave power at $500{ }^{\circ} \mathrm{C}$ for $5 \mathrm{~min}$. After the growth was completed, the wafer was slowly cooled to room temperature, and then the CNWs grown on interlayer-coated glass substrates were taken out from the chamber. The detailed experiment conditions are summarized in Tables 1 and 2.

Table 1. Deposition Conditions of the Interlayers via the RF Magnetron Sputtering System.

\begin{tabular}{cc}
\hline Parameters & Conditions \\
\hline Substrate lass & Below $1 \times 10^{-6} \mathrm{Torr}$ \\
Working pressure & $3 \times 10^{-3} \mathrm{Torr}$ \\
RF power & $50 \mathrm{~W}$ \\
Deposition temperature & Room temperature \\
Target & $\mathrm{Ni}, \mathrm{Ti}$ \\
Sputtering gas & $\mathrm{Ar}, 40 \mathrm{sccm}$ \\
Rotation speed & $1700 \mathrm{rph}$ \\
Deposition time & $5 \mathrm{~min}, 10 \mathrm{~min}$, and $30 \mathrm{~min}$ \\
\hline
\end{tabular}

Table 2. Growth Conditions of the CNWs.

\begin{tabular}{cc}
\hline Parameters & Conditions \\
\hline Substrate & Interlayer-coated glass substrates \\
Base pressure & Below $1 \times 10^{-5}$ Torr \\
Working pressure & $1.1 \times 10^{-2}$ Torr \\
\hline
\end{tabular}


Table 2. Cont.

\begin{tabular}{cc}
\hline Parameters & Conditions \\
\hline Microware power & $1200 \mathrm{~W}$ \\
Substrate temperature & $500{ }^{\circ} \mathrm{C}$ \\
Reaction gas & $\mathrm{CH}_{4}: 20 \mathrm{sccm}$ \\
Reaction gas & $\mathrm{H}_{2}: 40 \mathrm{sccm}$ \\
Growth time & $5 \mathrm{~min}$ \\
\hline
\end{tabular}

\subsection{Analysis and Measurement}

We used field emission scanning electron microscopy (FE-SEM, Hitachi S-4800, Krefeld, Germany) to analyze the types and properties of the CNWs on interlayer-coated glass substrates. In addition, Hall measurement system (Ecopia, HMS-3000, Toronto, ON, Canada) and UV-Vis equipment (SCINCO, S-3100, Seoul, Korea) were used to verify the electrical characteristics of grown CNWs and their light transmittance, respectively.

\section{Results and Discussion}

\section{Surface and Structural Characteristics}

Figure 1 shows the surficial and cross-sectional SEM images of the synthesized CNWs directly on glass substrates. As shown in the figure, the CNWs were grown into uniform shapes and to heights of about $805 \mathrm{~nm}$. However, the cross-sessional and planar FE-SE images of the CNWs reveal a gap between the two layers of material. In particular, the dark grey color is the glass substrate, the thin black layer is the gap and a thin intermediate layer is the carbon layer. This phenomenon is thought to be caused by the low adherence to the glass substrate of the CNWs [16] as well as the influence of low growth temperature.

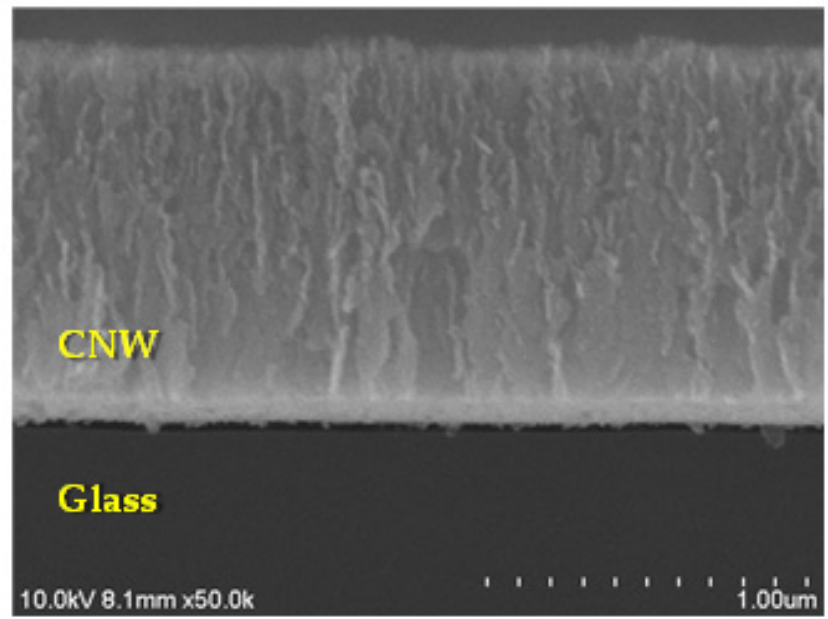

(a)

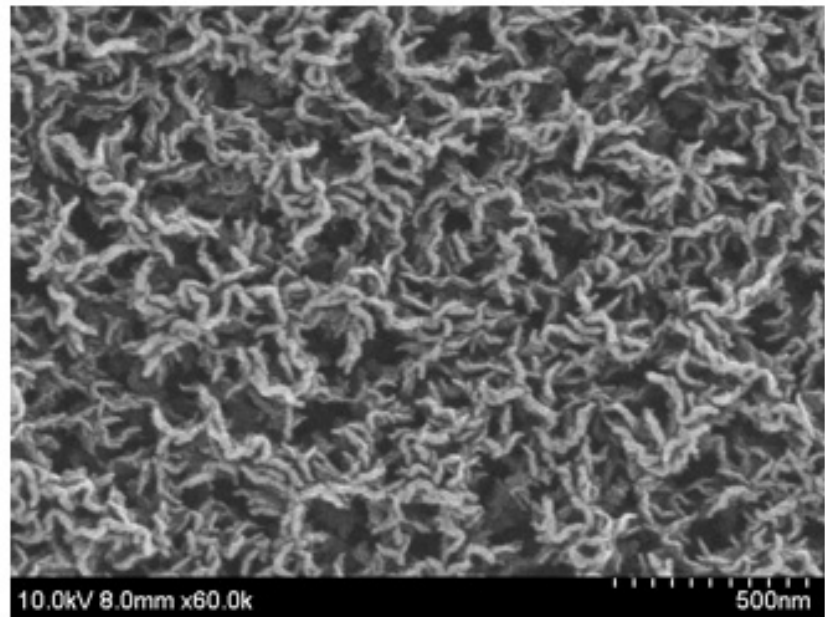

(b)

Figure 1. FE-SEM images of the grown CNW on the glass substrate: (a) cross-sectional image and (b) surficial image.

Figure 2 shows the surface FE-SEM images of the grown CNWs after Ni or Ti were deposited on the glass substrates. In both types of interlayers, the basis of the CNW shape was established better than in the $\mathrm{CNW}$ grown directly on the substrate. According to many studies that have been performed, the $10 \mathrm{~nm}$ Ni metal layer acted as a catalyst, and CNT was grown instead of CNWs [17]. However, all interlayers in this study were created with thicknesses larger than $10 \mathrm{~nm}$, allowing the CNWs to develop successfully on stable substrates. For both types of the inserted interlayer on substrates, each of the synthesized CNWs formed a thin monolayer with a unique maze-like structure, and the two-dimensional carbon seats were well grown vertically on the interlayers. 


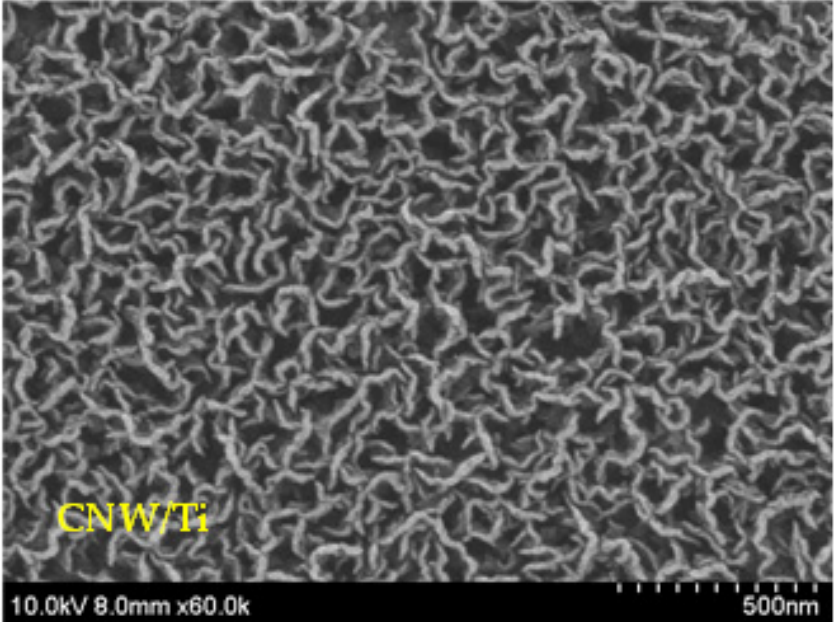

$(\mathbf{a}-1)$

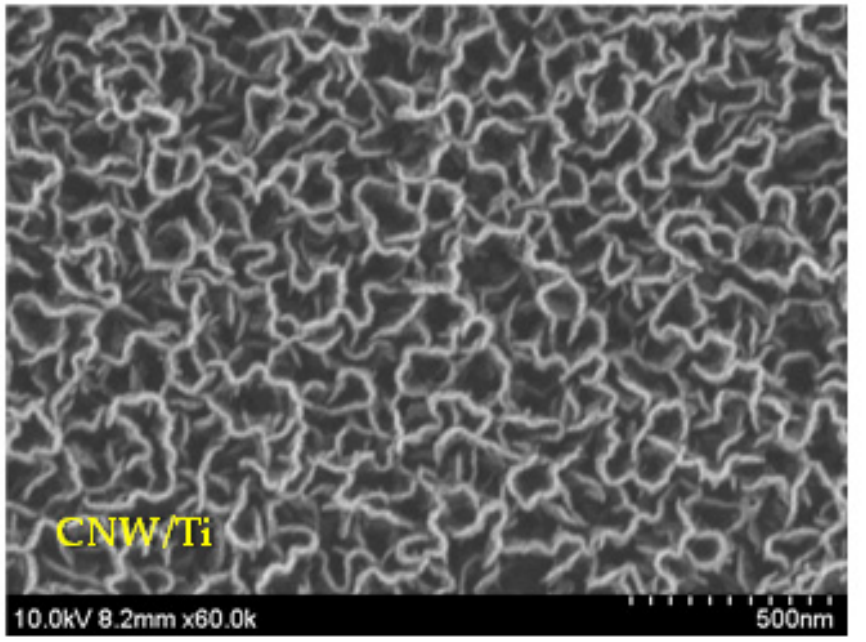

(b-1)

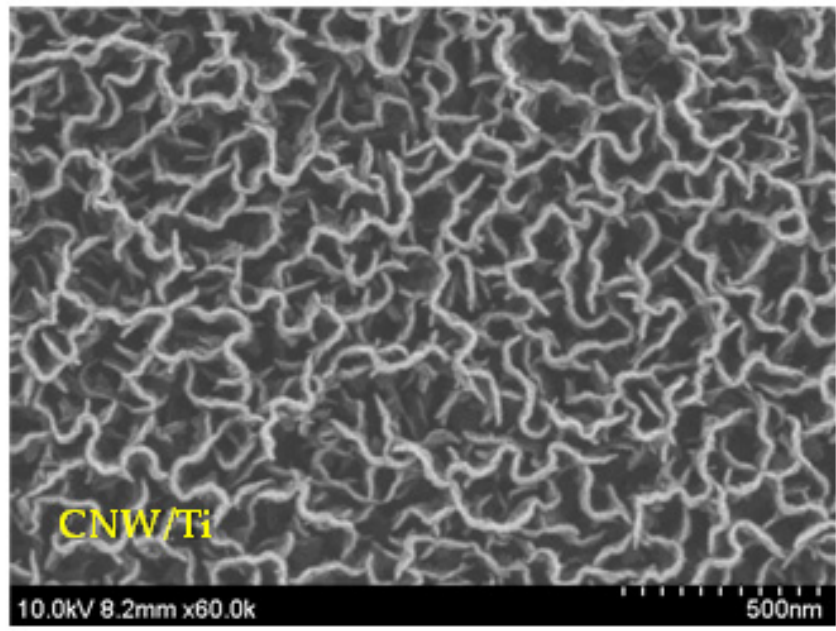

(c-1)

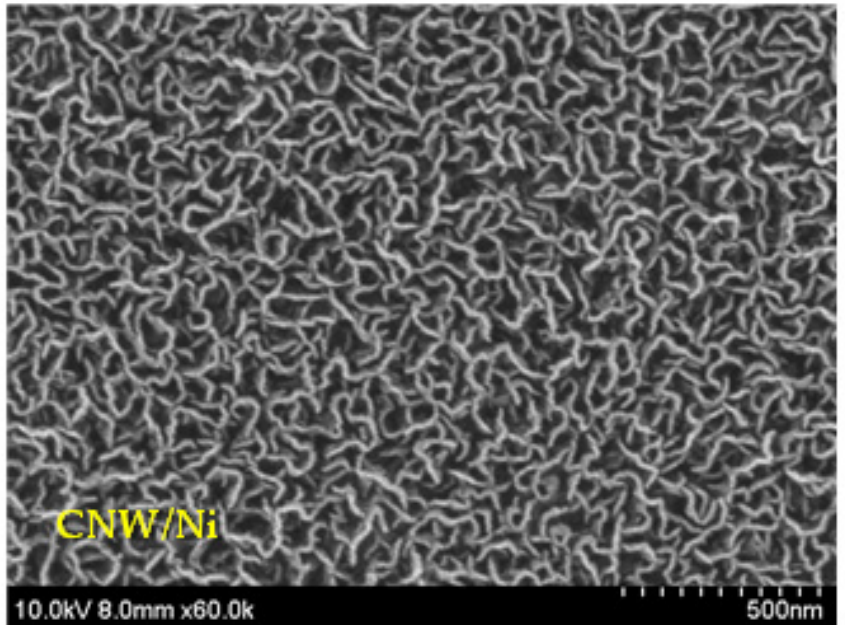

(a-2)

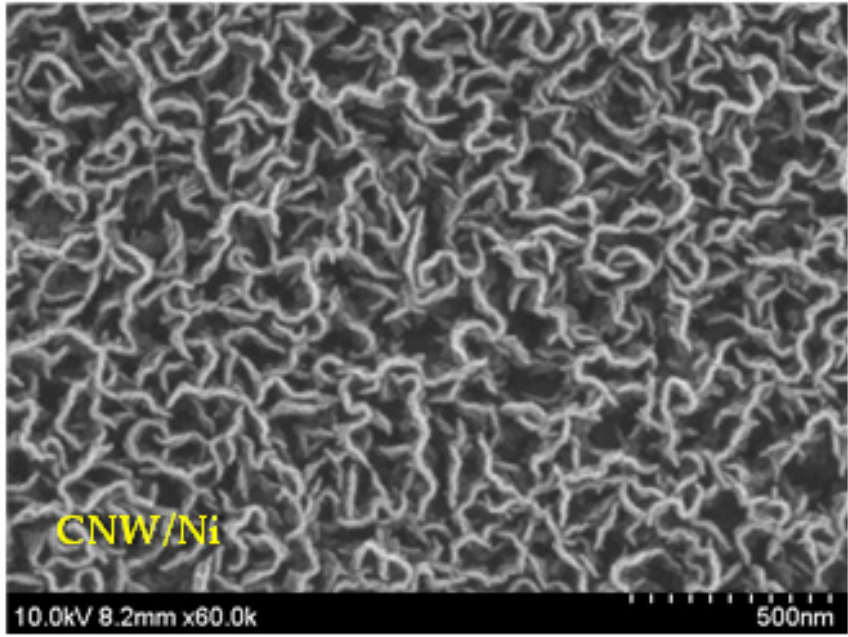

(b-2)

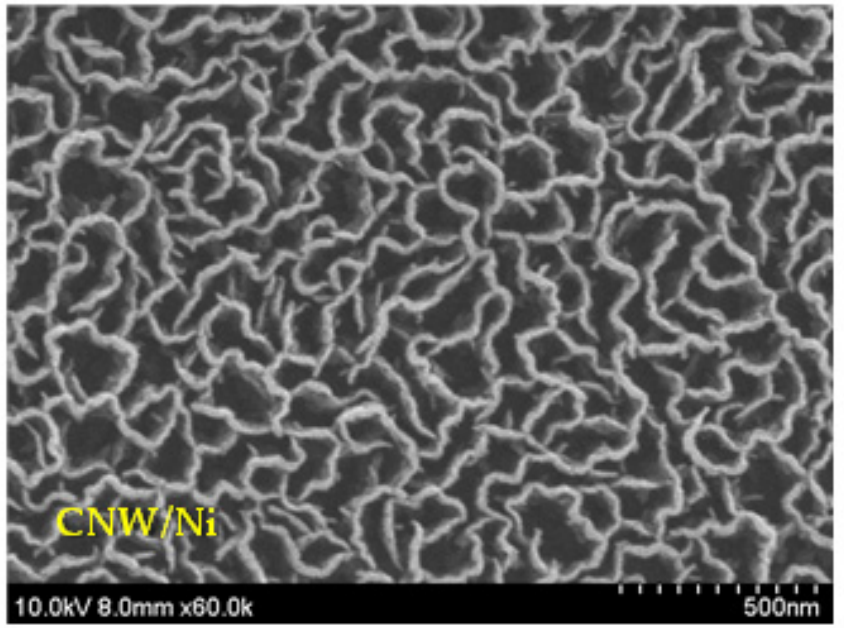

(c-2)

Figure 2. Surface SEM images of the grown CNWs depending on the different interlayers and deposition time: (a-1,a-2): $5 \mathrm{~min}$; (b-1,b-2): $10 \mathrm{~min}$; and (c-1,c-2): $30 \mathrm{~min}$. 
Furthermore, when comparing the density of a CNW synthesized on the $\mathrm{Ni}$ and $\mathrm{Ti}$ interlayers, the density of the CNW synthesized on the Ni interlayer was higher than the density of the CNW synthesized on the Ti interlayer. This may be due to the difference in thermal conductivity of nickel and titanium on glass substrates as well as the fact that $\mathrm{Ti}$ oxidizes to $\mathrm{TiO}_{2}$ when exposed to the atmosphere, reducing the uniformity of the substrate utilized for CNW development. The change in the CNW shapes can also be identified based on the sputtering duration $(5,10$, and $30 \mathrm{~min})$. When the deposition period was extended, the form and density of CNWs on Ti-interlayer-coated glass substrates were essentially the same; however, there was a substantial variation on the Ni-interlayer-coated glass substrates.

Figure 3a-c shows the cross-sectional FE-SEM images of the CNWs after the interlayer was inserted between the CNW and the glass substrate. Figure $3 \mathrm{~d}$ shows cross-sectional SEM images of the CNWs at 30 min of deposition time, depending on the different interlayers. It is difficult to confirm the thickness of the interlayers by FE-SEM measurement because the thickness of the coated film is very thin when the deposition period is less than $30 \mathrm{~min}$. Based on these results, Figure 4 shows that the lengths of the CNWs vary depending on the deposition time of the interlayers. It was found that there were similar trends for both types of used interlayers; the CNWs became significantly longer as the deposition time was extended from 5 to $30 \mathrm{~min}$, and all samples synthesized on the interlayer showed a higher height than the originally grown CNW due to the influence of the interlayer thickness. These graphs confirm that the height of CNWs grown on the Ni interlayer increased from $805 \mathrm{~nm}$ to $856 \mathrm{~nm}$, and the height of CNWs grown on the Ti interlayer increased from $805 \mathrm{~nm}$ to $839 \mathrm{~nm}$. These also indicate that the $\mathrm{Ni}$ and Ti interlayers not only improved the adhesion of CNWs to the glass substrate but also promoted their height. However, due to the effect of different deposition rates, the height of CNW produced on the Ti-interlayer-coated glass substrates was lower than on the Ni-interlayer-coated glass substrates for the same condition. In particular, the height difference of the CNWs according to deposition time was greatest at $30 \mathrm{~min}$.

Figure $5 \mathrm{a}, \mathrm{b}$ shows the transmittance waveforms depending on the wavelength, while Figure $5 \mathrm{c}$ presents the average transmittance of the $400-800 \mathrm{~nm}$ wavelength. The average light transmittance of CNWs directly on glass substrates is the highest at roughly $39.4 \%$. Although the height of the CNW changed insignificantly after the interlayers were inserted at 5 min deposition time, the average transmittance dramatically reduced to about $16.10 \%$ for the Ti interlayer and $9.2 \%$ for the Ni interlayer. This seems to indicate that the interlayers have a strong light absorption capability. In addition, Figure $5 \mathrm{c}$ shows that the average transmittance of CNWs synthesized on both $\mathrm{Ni}$ and Ti interlayers decreased when the deposition time increased. Based on the SEM analysis, the CNW synthesized on the Ni interlayer was higher and denser than the CNW synthesized on the Ti interlayer, thereby resulting in a lower average transmittance.

Figure 6 shows the graph in which the resistivity and the conductivity characteristics measured by using the Hall measurement are arranged. The resistivity graph shows that the resistance values of all the grown CNWs on the used interlayer appeared to be lower than those of the grown CNWs without an interlayer. Based on the SEM analysis, the CNWs that were synthesized on the interlayer-coated glass substrate were higher and far more densely grown than on the glass substrate. The resistivity reduced as the deposition time increased. The resistivity is lowest at $30 \mathrm{~min}$ of deposition time, roughly $0.06 \Omega . \mathrm{cm}$ for Ti interlayers and $0.05 \Omega . \mathrm{cm}$ for $\mathrm{Ni}$ interlayers. For both $\mathrm{Ni}$ and Ti interlayers, the maximum resistivity fell by $88.1 \%$ and $85.71 \%$, respectively, when compared to the minimum value. The conductivity of the synthesized CNWs can be expressed as the reciprocal of resistivity. Furthermore, the graph shows that the Ni interlayer enhanced the conductivity of the CNW more effectively than the Ti interlayer under the same synthesis conditions. This is due to the fact that Ni has a higher electrical conductivity than Ti [18]. Another explanation is that Ti not only exhibits less deposition than $\mathrm{Ni}$, but is also oxidized and transformed into $\mathrm{TiO}_{2}$ when it is exposed to the atmosphere at room temperature. 


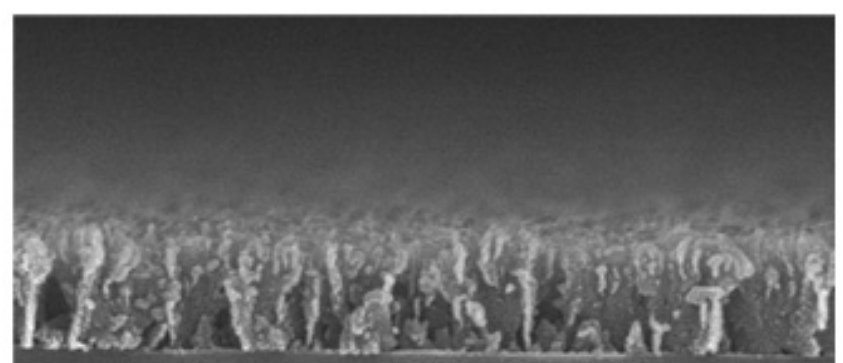

$\mathrm{CNW} / \mathrm{Ti}$

$10.0 \mathrm{kV} 8.0 \mathrm{~mm} \times 35.0 \mathrm{k}$

(a-1)

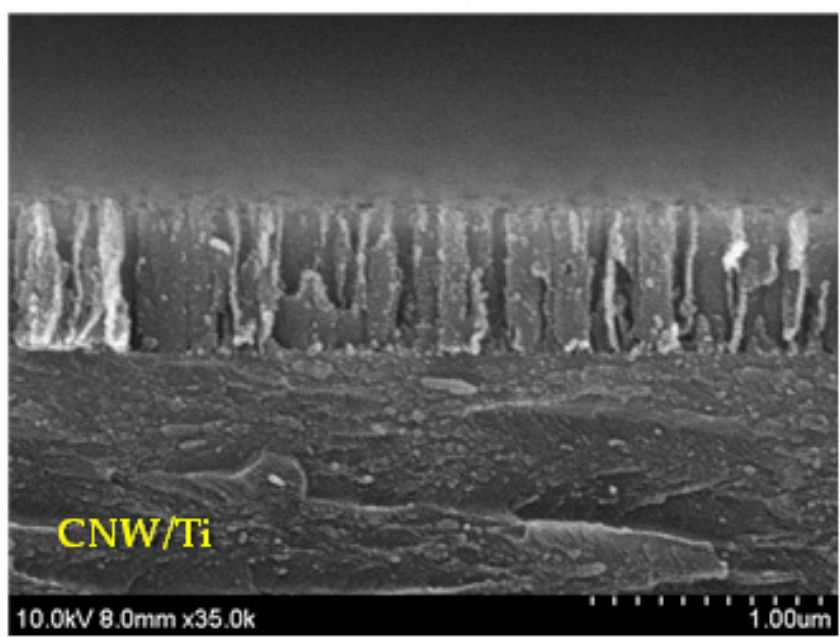

(b-1)

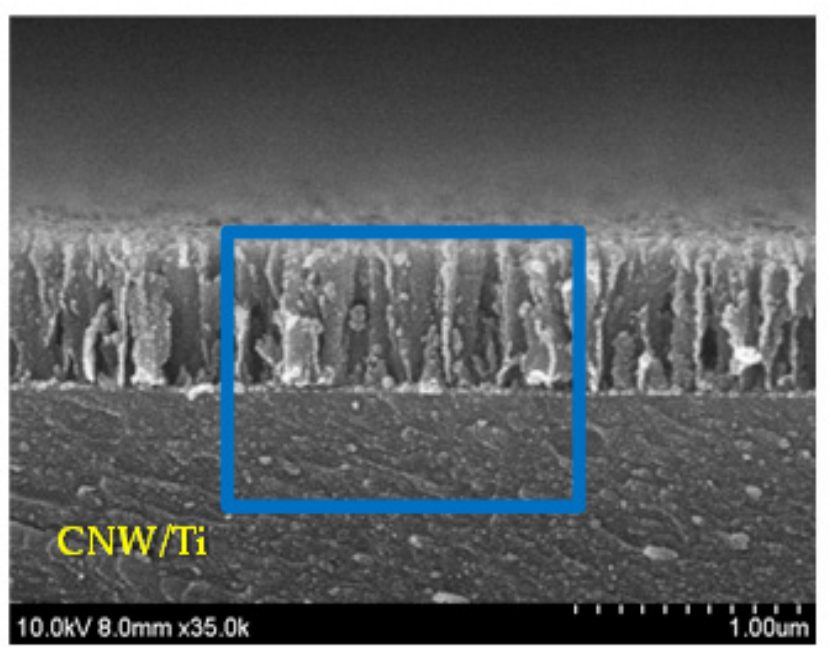

(c-1)

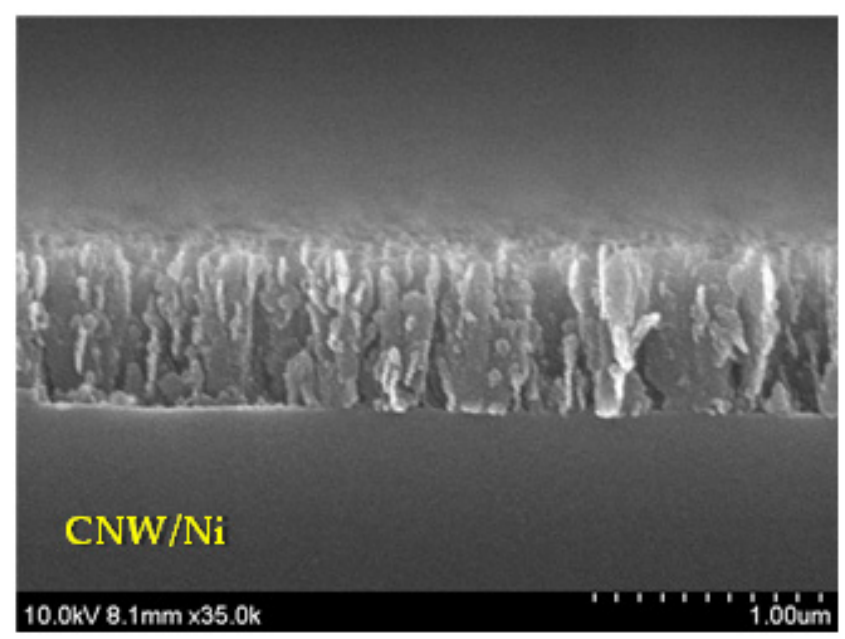

(a-2)

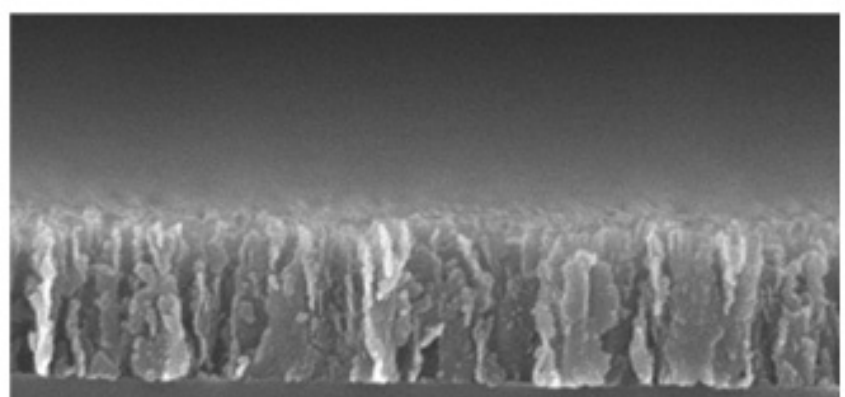

$\mathrm{CNW} / \mathrm{Ni}$

10.0kV 8.1 mm $\times 35.0 \mathrm{k}$ 1.00 um

(b-2)

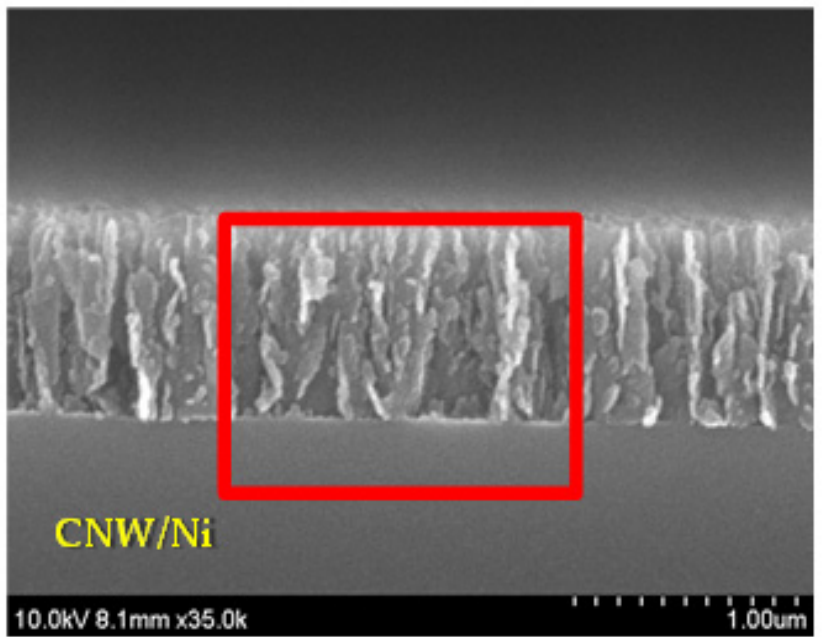

(c-2)

Figure 3. Cont 


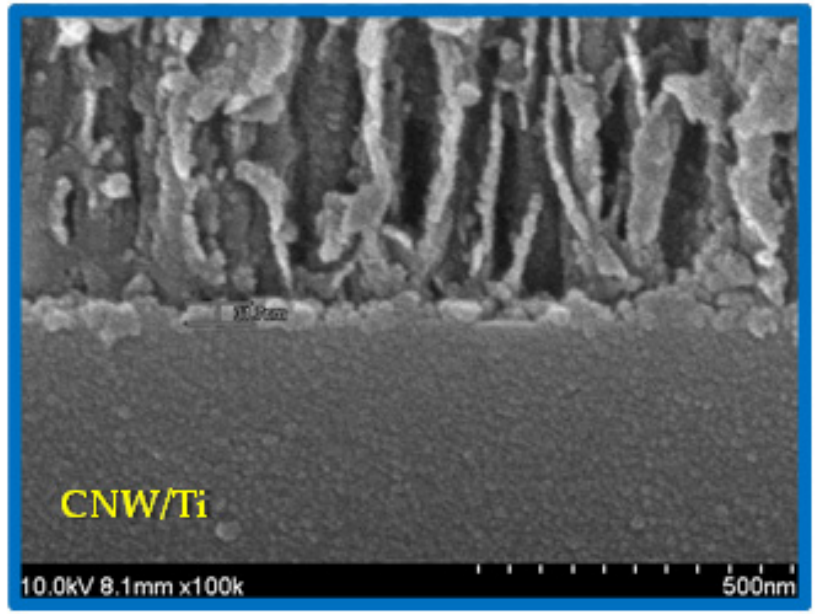

(d-1)

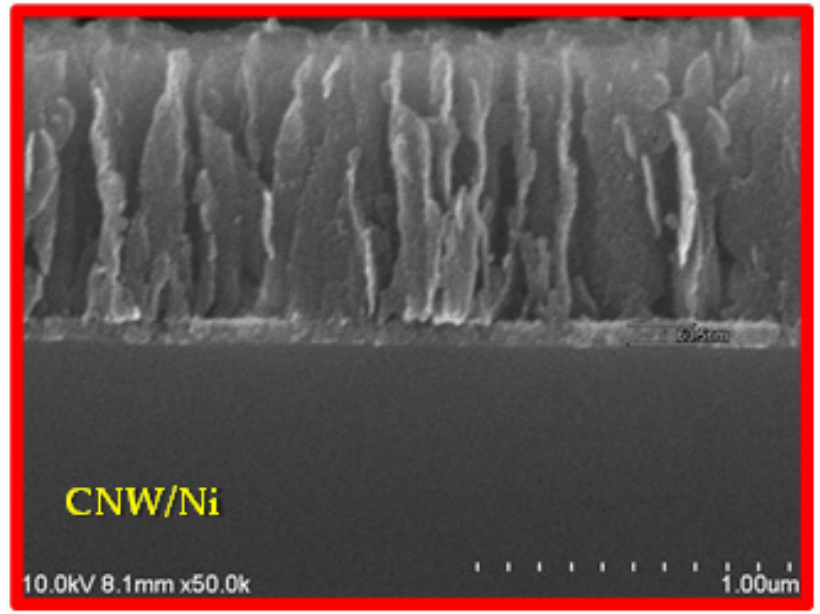

(d-2)

Figure 3. Cross-sectional SEM images of the CNWs depending on the different interlayers and their deposition time: (a-1,a-2): $5 \mathrm{~min}$; (b-1,b-2): $10 \mathrm{~min}$; (c-1,c-2): $30 \mathrm{~min}$; and (d-1,d-2): $30 \mathrm{~min}$.

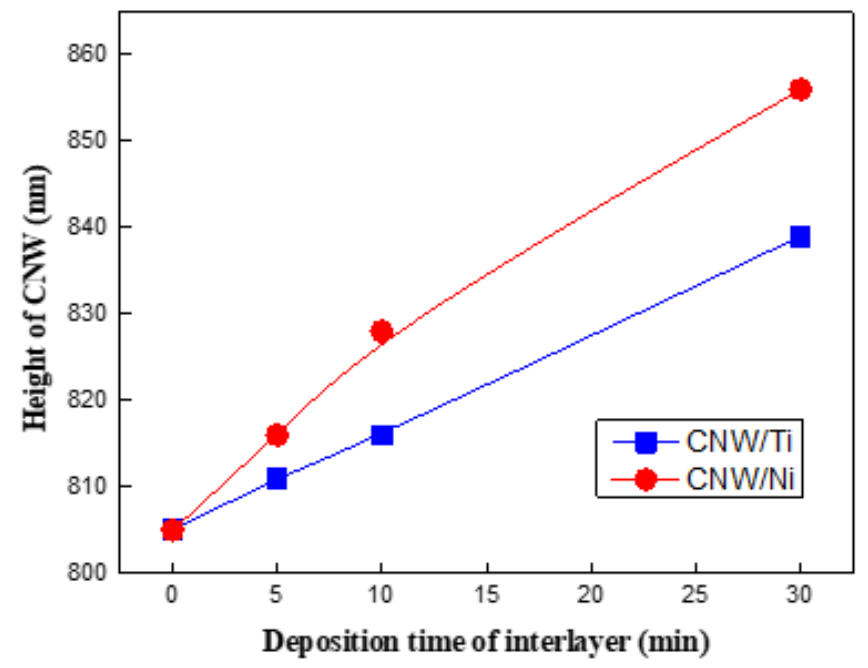

Figure 4. The height of the grown CNWs depends on the interlayers and deposition time.

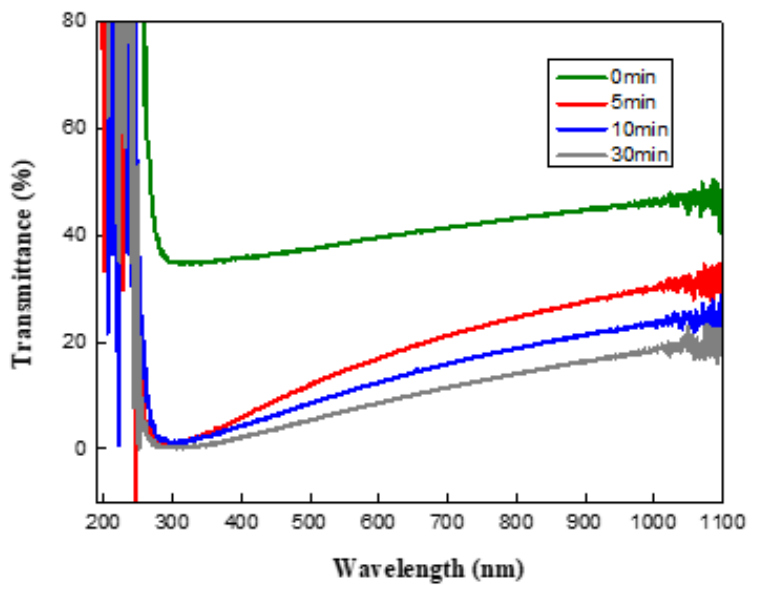

(a)

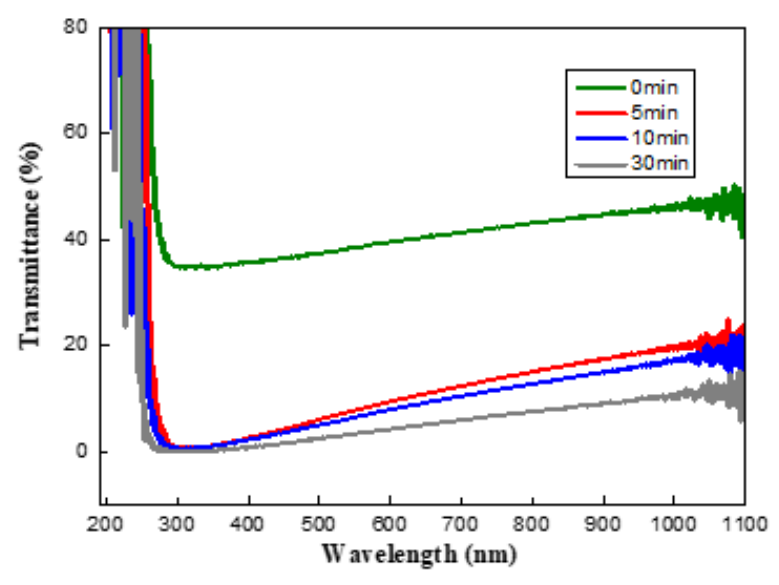

(b)

Figure 5. Cont. 


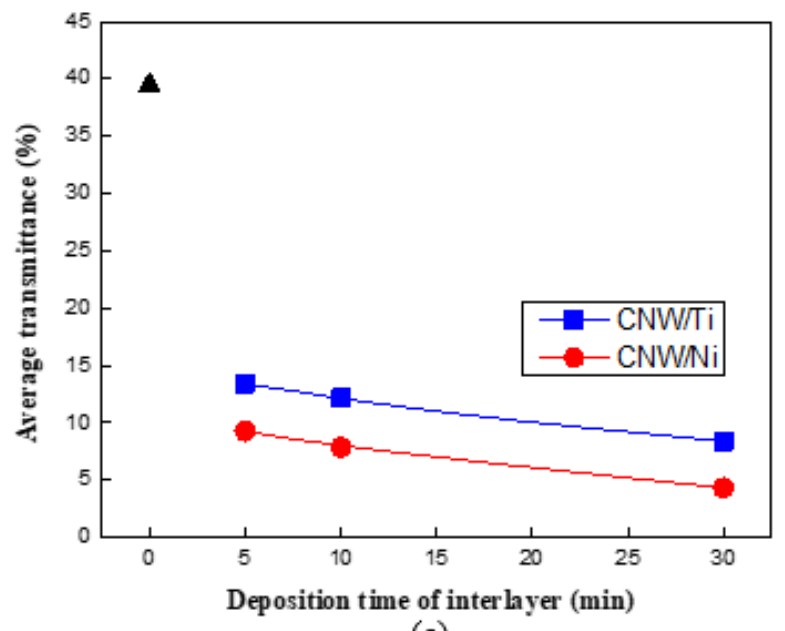

(c)

Figure 5. Light transmittance of the CNWs according to the different interlayers and deposition time: (a) $\mathrm{CNW} / \mathrm{Ti} /$ glass, (b) $\mathrm{CNW} / \mathrm{Ni} /$ glass, and (c) average transmittance of the $400-800 \mathrm{~nm}$ wavelength.

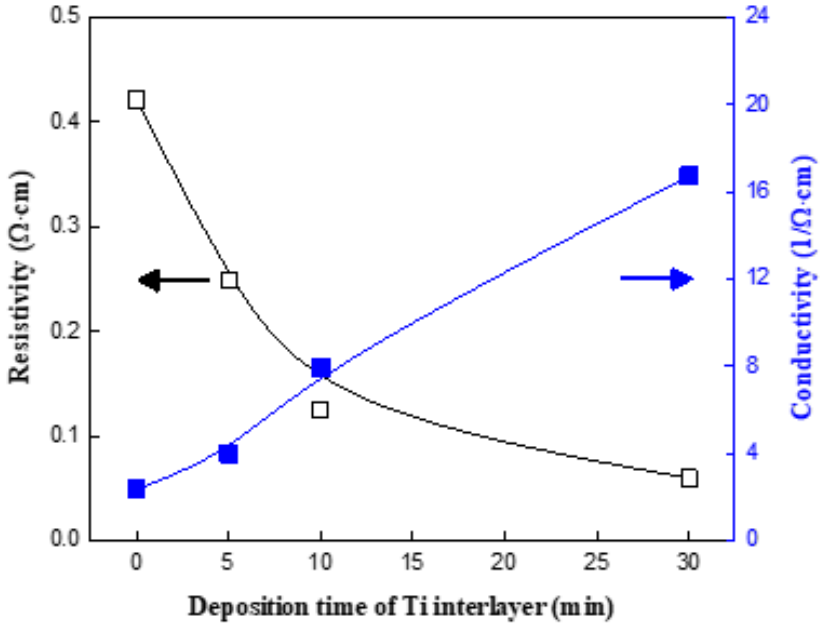

(a)

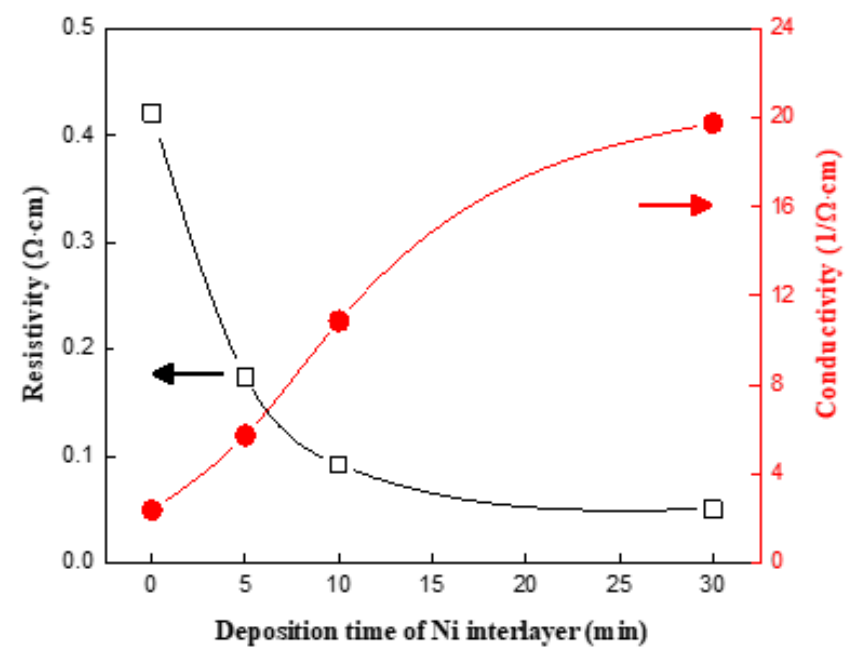

(b)

Figure 6. The resistivity and conductivity of the CNWs synthesized on an interlayer: (a) $\mathrm{CNW} / \mathrm{Ti} /$ glass substrate and $(\mathbf{b}) \mathrm{CNW} / \mathrm{Ni} /$ glass substrate. 


\section{Conclusions}

In this research, the effect of the interlayers according to deposition time was investigated in order to improve the use of CNWs. The CNWs were synthesized on either a Ni-interlayer-coated glass substrate or Ti-interlayer-coated glass substrate via microwave PECVD using a mixture of $\mathrm{CH}_{4}$ and $\mathrm{H}_{2}$ gases as the reaction gases. The FE-SEM analysis confirmed that the growth height and shape and growth density were different between CNWs grown directly on the glass substrate and CNWs grown on the interlayer. However, the adhesion of CNWs and their height were improved. Moreover, compared to the Ti interlayer, $\mathrm{CNW}$ s grown on the $\mathrm{Ni}$ interlayer were higher and had more density. According to the light transmittance analysis, the average transmittance dropped as the deposition time rose for both types. The resistivity in the Hall measurements appeared to have also decreased more significantly in all the synthesized CNWs than in the as-deposited CNW. Furthermore, the most outstanding resistivity and conductivity were observed at the deposition time of $30 \mathrm{~min}$. The CNW's electrical characteristics improved when the interlayers were inserted.

Based on this study, the CNWs grown on nickel and titanium interlayers not only presented with excellent adhesion, but also improved electrical characteristics, especially when the Ni interlayers were used. Therefore, carbon-based materials synthesized on either a nickel or titanium interlayer are likely to be used in a wide range of applications through additional studies in the future.

Author Contributions: Conceptualization, M.T.T., S.K.; Formal analysis, M.T.T.; Investigation, M.T.T.; Writing—original draft, M.T.T.; Data curation, M.T.T.; Writing—review \& editing, M.T.T., H.K., J.-H.K., Y.-K.Y., and W.C.; Supervision, W.C. All authors have read and agreed to the published version of the manuscript.

Funding: This research received no external funding.

Institutional Review Board Statement: Not applicable.

Informed Consent Statement: Not applicable.

Data Availability Statement: Not applicable.

Acknowledgments: This study was financially supported by Hanbat National University Financial Accounting Research Fund, 2019 year.

Conflicts of Interest: The authors declare no conflict of interest.

\section{References}

1. Novoselov, K.S.; Geim, A.K.; Morozov, S.V.; Jiang, D.; Zhang, Y.; Dubonos, S.V.; Grigorieva, I.V.; Firsov, A. Electric Field Effect in Atomically Thin Carbon Films. Science 2004, 306, 666. [CrossRef] [PubMed]

2. Lee, C.; Wei, X.; Kysar, J.W.; Hone, J. Measurement of the elastic properties and intrinsic strength of monolayer graphene. Science 2008, 321, 385. [CrossRef]

3. Divya, K.C.; Østergaard, J. Battery energy storage technology for power systems-An overview. Electr. Pow. Syst. Res. 2009, 79, 511. [CrossRef]

4. Huang, Y.; Cai, J.; Zheng, S.; Guo, Y.J. Fabrication of a high-performance Pb-PtCu/CNT catalyst for methanol electro-oxidation. Power Sources 2012, 210, 81. [CrossRef]

5. Yang, S.; Cheng, Y.; Xiao, X.; Pang, H. Development and application of carbon fiber in batteries. Chem. Eng. J. 2019, 384, 123294. [CrossRef]

6. Li, Z.; Wang, L.; Yu, L.; Feng, Y. Carbon-based functional nanomaterials: Preparation, properties, and application. Compos. Sci. Technol. 2019, 179, 10-40. [CrossRef]

7. Fiorani, A.; Merino, J.P.; Zanut, A.; Cariado, A.; Valenti, G.; Prao, M.; Paolucci, F. Advanced carbon nanomaterial for electrochemiluminescent biosensor application. Curr. Opin. Electrochem. 2019, 16, 66-74. [CrossRef]

8. Kuang, Q.; Xie, S.Y.; Jiang, Z.Y.; Zhang, X.-H.; Xie, Z.-X.; Huang, R.-B.; Zheng, L.-S. Low temperature solvothermal synthesis of crumple carbon nanosheets. Carbon 2004, 42, 1737. [CrossRef]

9. Lee, S.-W.; Muoth, M.; Helbling, T.; Mattmann, M.; Hierold, C. Suppression of resist contamination during photolithography on carbon nanomaterials by a sacrificial layer. Carbon 2014, 66, 295-301. [CrossRef]

10. Filippidou, M.K.; Chatzichristidi, M.; Chatzandroulis, S. A fabrication process of flexible IDE capacitive, chemical sensors using a two-step lift-off method based on PVA patterning. Sens. Actuators B Chem. 2019, 284, 7-12. [CrossRef] 
11. Aleksandrova, M.; Kurtev, N.; Videkov, V.; Tzanova, S.; Schintke, S. Material alternative to ITO for transparent conductive electrode in flexible display and photovoltaic devices. Microelectron. Eng. 2015, 145, 112-116. [CrossRef]

12. Barksdale, J. (Ed.) Titanium, Its Occurrence, Chemistry, and Technology; The Ronald Press: New York, NY, USA, $1966 ;$ p. 185.

13. Kong, S.H.; Kim, H.W.; Shin, Y.S.; Kim, M.I. The Effect of Titanium Interlayer on the Adhesion Properties of TiN Coating. J. Korea Soc. Heat Treat. 1992, 5, 1-12.

14. Wen, F.; Zhao, J.; Yuan, M.; Wang, J. Influence of Ni interlayer on interfacial microstructure and mechanical properties of Ti-6Al-4V/AZ91D bimetals fabricated by a solid-liquid compound casting process. J. Magnes. Alloy. 2021, 9, 1382-1395. [CrossRef]

15. Kundu, S.; Chatterjee, S. Interfacial microstructure and mechanical properties of diffusion-bonded titanium-stainless steel joints using a nickel interlayer. Mater. Sci. Eng. A 2006, 425, 107-113. [CrossRef]

16. Choi, H.; Kwon, S.; Kang, H.; Kim, J.H.; Choi, W. Adhesion-Increased Carbon Nanowalls for the Electrodes of Energy Storage Systems. Energies 2019, 12, 4759. [CrossRef]

17. Lee, S.J.; Choi, W.S. Growth of Carbon Nanowalls on Metal-Coated Substrates via Microwave Plasma Enhanced Chemical Vapor Deposition. J. Nanosci. Nanotechnol. 2014, 14, 9174-9177. [CrossRef] [PubMed]

18. Helmenstine, A.M. Table of Electrical Resistivity and Conductivity, Science, Tech, Math. 2019. Available online: https://www. thoughtco.com/table-of-electrical-resistivity-conductivity-608499 (accessed on 9 December 2021). 